\title{
Theoretical Predication of the Synthesis of ReNCl
}

\author{
Xiuxiu $\mathrm{Fu}^{1}$, Ning Chen ${ }^{1, *}$, Xiuxia Liu ${ }^{2}$ and Yang $\mathrm{Li}^{3}$ \\ ${ }^{1}$ School of materials science and Engineering, University of Science and Technology Beijing, Beijing 100083, China \\ ${ }^{2}$ Weichai Power Co., Ltd. Quality department, Weifang 261000, China \\ ${ }^{3}$ Department of Engineering Science and Materials, University of Puerto Rico, Mayagüez, Puerto Rico 00681-9044, USA \\ *Corresponding author
}

\begin{abstract}
Using the idea of Materials Genome Initiative (MGI) for reference, by means of the First-principle calculation method, according to the known $\mathrm{MNCl}(\mathrm{M}=\mathrm{Zr}$, Hf) structure to build model, we systematically calculated and analysised the binding energy and reaction energy of two phases of lanthanon replaced ReNCl compounds. Finally, we established the mathematical model, predicted the synthesis of $\mathrm{ReNCl}$ theoretically.
\end{abstract}

Keywords-simulation; first-principles calculations; nitride chlorides

\section{INTRODUCTION}

$M \mathrm{~N} X(M=\mathrm{Zr}, \mathrm{Hf} ; X=\mathrm{Cl}, \mathrm{Br}, \mathrm{I})$ were reported by Jusa et al [1] in 1964 for the first time. Further, Yamanaka et al [2] [3] found it as solid lubricant and electrochromic material. Later, Yamanaka [4] also reported that $\mathrm{ZrNCl}$ and $\mathrm{HfNCl}$ had exhibited superconductivity properties by intercalating lithium in the interlayer. And the layered structure of $\mathrm{MNCl}$ is very conducive to the lithium intercalation/ deintercalation, so it also has a potential application for lithium ion batteries. These theoretical and experimental work create new fields for the application research of this kind of materials.

However, $M \mathrm{NCl}$ is difficult to synthesize, few $M \mathrm{NCl}$ compounds were experimentally confirmed currently. The $M$ mainly includes tetravalent element, such as $\mathrm{Ti}, \mathrm{Zr}$, Hf. As we all known that some of lanthanon have +4 valence, such as $\mathrm{Ce}$, $\mathrm{Pr}, \mathrm{Tb}$ etc. Doping or replacing lanthanon into the crystal lattice structure usually lead to some unique properties, because of its $4 f$ electronic character. In order to explore innovative $M \mathrm{NCl}$ compound with special physical and chemical properties, we using the idea of Materials Genome Initiative (MGI) which was proposed by U. S. President Barack Obama in 2011 [5] for reference, and basing on the reported $M \mathrm{NCl}$ structure, using the first-principle calculations method to replace lengthy and costly experimental Studys, systematically studied the stability of lanthanon (No.1-15) replaced $R e N C l$ compound. And theoretically predicted the synthetic of $\mathrm{ReNCl}$.

\section{RESEARCH METHOD}

So far the experimental results showed that $M \mathrm{NCl}(M=\mathrm{Zr}, \mathrm{Hf})$ crystal has two types, including the $\alpha$ phase type with $\mathrm{FeOCl}$ structure and the $\beta$ phase type with SmSI structure. Figure 1 shows the two different crystal structure models of $M \mathrm{NCl}$, (A) and (B) are $\alpha$ phase and $\beta$ phase respectively, $(\mathrm{C})$ is the crystal structure of $\mathrm{CeNCl}$ which is similar with the $\alpha$ phase.
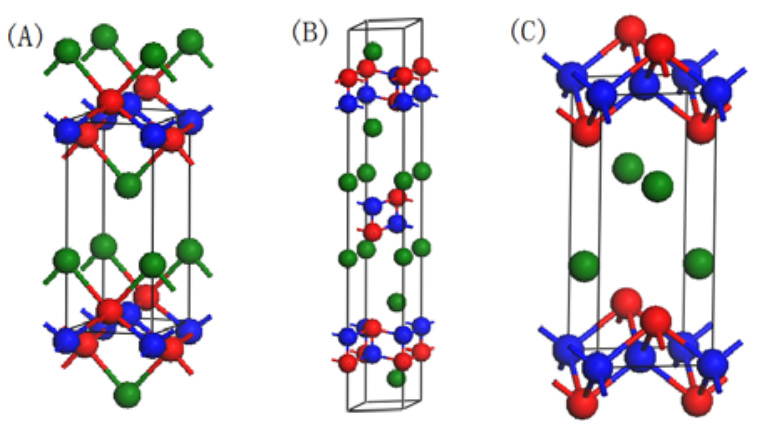

FIGURE I. CRYSTAL STRUCTURE MODELS: (A) $A$ PHASE OF $M$ NCL, (B) $B$ PHASE OF $M N C L$, (C) CENCL STRUCTURE

First-principle energy calculation is firstly performed to obtain total energy of any systems with known lattice parameters and atomic coordinates. In order to study the stability of the $\beta$ and $\alpha$ phase, it is vital to compare their binding energies $E_{\mathrm{B}}$. The binding energy $E_{B}$ is defined as the required energy to disassemble the compound into component atoms separated by infinite distance. The binding energy $E_{B}$ can be given as

$$
\mathrm{E}_{\mathrm{B}}=\sum E_{\text {Atom }}-E_{\text {Compound }}
$$

where $\sum E_{\mathrm{Atom}}$ and $\sum E_{\text {Compound }}$ correspond to the total energy of the isolated atoms and the compound, respectively. Ingeneral, the compound maybe stable if $\mathrm{E}_{\mathrm{B}}$ is positive. By comparing several different virtual $\mathrm{E}_{\mathrm{B}}$, we can confirm the most reasonable structure of the compound theoretically. The different of $E_{\mathrm{B}}$ in the two phases can be given as

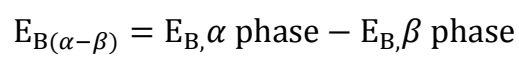

A positive $\mathrm{E}_{\mathrm{B}(\alpha-\beta)}$ indicates that the $\alpha$ phase are more stable than the $\beta$ phase - the more positive the $\mathrm{E}_{\mathrm{B}(\alpha-\beta)}$, the greater the $\alpha$ phase's stability. Ingeneral, if the binding energy of the $\alpha$ phase is larger than that of the $\beta$ phase, the reaction preferentially produces the $\alpha$ phase; otherwise, the $\alpha$ phase can not be created.

On the other hand, it's also essential that the compound can be synthesised, wether the reacting process happen or not can be judged by chemical reaction drive energy $E_{\mathrm{RD}}$, which is defined as the difference of the total binding energy between the reactant and the product for the chemical reactions as

$$
\mathrm{E}_{\mathrm{RD}}=\sum E_{\mathrm{B}} \text { (Product) }-\sum E_{\mathrm{B}} \text { (Reactant) }
$$

where $\sum E_{\mathrm{B}}$ (Product) and $\sum E_{\mathrm{B}}$ (Reactant) correspond to the total binding energy of the product and reactant, respectively. For the $\mathrm{ReNCl}$ synthetic reaction, which given as

$$
\mathrm{Re}+\mathrm{NH}_{4} \mathrm{Cl}=\mathrm{ReNCl}+2 \mathrm{H}_{2},
$$


the $\mathrm{E}_{\mathrm{RD}}$ can be defined as

$$
\mathrm{E}_{\mathrm{RD}}=E_{\mathrm{B}}\left(\operatorname{ReNCl}+2 \mathrm{H}_{2}\right)-E_{\mathrm{B}}\left(\mathrm{Re}+\mathrm{NH}_{4} \mathrm{Cl}\right) .
$$

Ingeneral, if $\mathrm{E}_{\mathrm{RD}}>0$, the $R e \mathrm{NCl}$ can be synthesised; otherwise, the $\mathrm{ReNCl}$ can not be created.

The results were obtained by means of first-principle calculation procedure as implemented in the computer code CASTEP[6] of Material Studio produced by Accelrys company. Through the establishment of model, geometry optimization, task set, calculated the total energy of structures, we calculate $E_{r}$ according to the formula given former. The CASTEP module is based on density functional theory (DFT), with Projector Augmented Wave (PAW) pseudo-potentials and plane wave basis set. The exchange-correlation Perdew-Burke-Ernzerhof (PBE) [7] functional was of the GGA-type. We chose the calculation with Ultrasoft-pseudopotential, kinetic energy cutoff for the plane wave basis set was $320 \mathrm{e} V$, the convergence precision was $1.0 \times 10^{-4} \mathrm{e} V$ atom $^{-1}$, and we specify spin direction of all the magnetic elements, ultimate atom displacement and stress of virtual process were less than $0.002 \AA$ and $0.1 \mathrm{GPa}$, respectively. $\mathrm{K}$ point mesh set as medium option, which are $2 \times 4 \times 4$ and $4 \times 4 \times 4$ corresponds to $\mathrm{CeNCl}$ with $\alpha$ phase and $\beta$ phase respectively

\section{RESULTS AND DISCUSSION}

According to the crystal model and method introduced above, we systematically calculated the binding energy of $\alpha$ and $\beta$ phase of lanthanon replaced $R e \mathrm{NCl}$, and in order to discuss the synthesis problem, we also calculated the corresponding $\mathrm{E}_{\mathrm{RD}}$ (Calculated $\mathrm{NH}_{4} \mathrm{Cl}$ and $\mathrm{H}_{2}$ with the same crystal conditions, $27.340 \mathrm{e} V$ and $-6.778 \mathrm{e} V$ respectively). One drawing is made with $\mathrm{E}_{\mathrm{RD}}$ as abscissas and $\mathrm{E}_{\mathrm{B}(\alpha-\beta)}$ as ordinate, which shown in figure 2 below. When $\mathrm{E}_{\mathrm{RD}}>0, R e \mathrm{NCl}$ can exist, and if the data point is located on $\alpha$ stable region, indicates that $R e \mathrm{NCl}$ exists in the $\alpha$ phase theoretically; if the data point is located on the zone of $\beta$ stability, indicates that $\operatorname{ReNCl}$ exists in the $\beta$ phase.

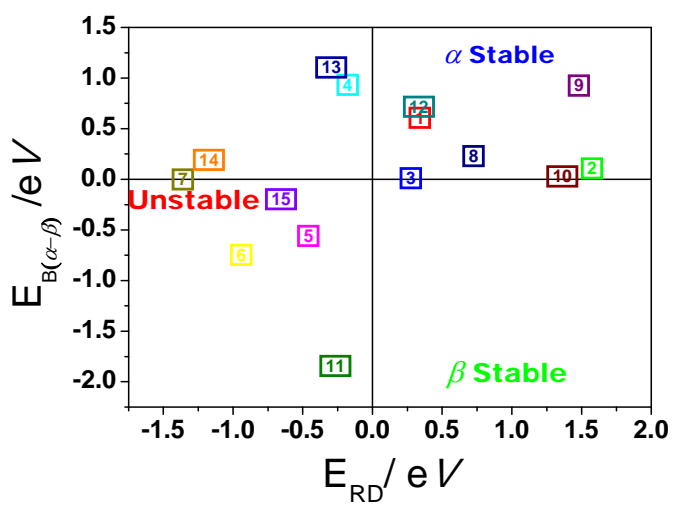

FIGURE II. THEORETICAL SYNTHESIS PREDICTION CHART OF RENCL. NO. 1 15 REFERS TO THE ELEMENT LA LU OF LANTHANON

Figure 2 shows that the data points of $\mathrm{CeNCl}, \mathrm{DyNCl}$ and $\mathrm{TbNCl}$ are on the $\alpha$ stable region, and they have large $\mathrm{E}_{\mathrm{RD}}$, which between $1.0 \mathrm{e} V \sim 2.0 \mathrm{e} V$, so $\mathrm{CeNCl}$, and $\mathrm{DyNCl} \mathrm{TbNCl}$ have possibilities for synthesis, and $\mathrm{CeNCl}$ compound has the maximum value, indicating that $\mathrm{CeNCl}$ is most likely to synthesis theoretically. $\mathrm{E}_{\mathrm{RD}}=0.7 \mathrm{e} V$ for $\mathrm{GdNCl}$ compound, so $\mathrm{GdNCl}$ may be able to synthesis. The PrNCl, LaNCl and ErNCl compounds are on the stable region, but their $\mathrm{E}_{\mathrm{r}}$ value are under $0.5 \mathrm{e} V$, so theoretically they are less likely to synthesis. Because the date point is on the unstable region, compound of $\mathrm{NdNCl}$. $\mathrm{PmNCl}$ and $\mathrm{SmNCl}$ does not have the necessary conditions for synthesis, theoretically, they are almost impossible to synthesis. The $\mathrm{CeNCl}$ compound with $\alpha$ phase in reference [8] was the only lanthanon replaced $\mathrm{ReNCl}$ material that has been reported. Based on the calculation results above, we synthesized $\mathrm{TbNCl}$ [9] and $\mathrm{GdNCl}$ [10] with $\alpha$ phase successfully, which is consistent with the theoretical prediction results.

\section{CONCLUSION}

This paper used simulation calculation method, using Firstprinciple calculation method, established the relationship between $\mathrm{E}_{\mathrm{B}}$ and $\mathrm{E}_{\mathrm{RD}}$ of $\alpha$ and $\beta$ phase of $R e \mathrm{NCl}$ compound. theoretically predicted the synthesis of $\mathrm{ReNCl}$, The experimental results confirms the validity of the theoretical prediction results in some way. The method of computational simulation combined with experiment research greatly shorten the cycle of new materials research and save materials, not only to guide the synthesis of $R e \mathrm{NCl}$ compound, but also to provide a reference for other new materials research.

\section{ACKNOWLEDGMENT}

This research has been supported by the National Basic Research Program of China (973 Program, No. 2012CB215405), thanks.

\section{REFERENCES}

[1] M. Ohashi, S. Yamanaka, M. Sumihara, M Hattori, "Lithium intercalation in layer structured compound $\beta-Z r N C l$," J. Inclusion. Phenom, vol. 2, pp. 289-295, March 1984.

[2] J. Robert, and F. Hans, "Die Kristallstruktur von $\beta-\mathrm{ZrNCl}$ und $\beta-\mathrm{ZrNBr}$," Z. Anorg. Allg. Chem, vol. 332, pp. 173-178, January 1964.

[3] S. Yamanaka, M. Ohashi, M. Sumihara, M. Hattori, "Lithium intercalation and electrochromism in .BETA-ZrNCl layered crystal." Chem. Lett, pp. 1403-1406, June 1984.

[4] S. Yamanaka, H. Kawaji, K. I. Hotehama, M. Ohashi, "A new layerstructured nitride superconductor. Lithium-intercalated ?-zirconium nitride chloride, LixZrNCl." Adv. Mater, vol. 8, pp. 771-774, September 1996.

[5] Materials genome initiative for global competitiveness. Washington: National Science and Technology Council, 2011.

[6] S. J. Clark, M.D. Segall, C.J. Pickard, P. J. Hasnip, M. I. J. Probert, R. Keith, Refson, C. P. Mike, "First principles methods using CASTEP." Z. Kristallogr, vol. 220, pp. 567-570, September 2009.

[7] B. Hammer, L. B. Hansen, and J. K. Nørskov, "Improved adsorption energetics within density-functional theory using revised Perdew-BurkeErnzerhof functionals." Phys. Rev. B, vol. 59, pp. 7413-7421, March 1999.

[8] G. M. Ehrlich, M. E. Badding, N. E. Brese, S. S. Trail, F. J. DiSalvo, "New cerium nitride chlorides: $\mathrm{Ce}_{6} \mathrm{Cl}_{12} \mathrm{~N}_{2}$ and CeNCl." J. Alloy. Compd, vol. 235, pp. 133-134, March 1996.

[9] X. X. Fu, N. Chen, X. X. Liu, Y. Li, unpublished.

[10] N. Chen, X. Liu, Y. Liu, Y. Li, J. Lu, K. Lu, et al. "Study on novel rareearth nitride chlorides $\mathrm{GdNCl}$ and $\mathrm{Gd}_{2} \mathrm{~N}_{2} \mathrm{Cl}$," APS March Meeting 2013, vol. 58, March 2013. 